\title{
Study on Effective Construction of High Quality English Classroom
}

\author{
Model \\ Lu Wang $^{1}$ \\ ${ }^{1}$ Qiqihar Medical University, Qiqihar, Heilongjiang, 161000 \\ Proj: Qiqihar City, Heilongjiang Province, Federation of Social Sciences Funds Projects "Medical \\ Colleges English High Quality Model Innovation" \\ 346591653@163.com
}

KEYWORDS: English Teaching Model; High Quality Teaching, Model Construction

\begin{abstract}
Efficient classroom teaching refers to the efficiency or effectiveness can have a very high goal to reach the classroom, specifically refers to the class on the basis of valid. Completion of teaching tasks and achieve have higher goals of teaching efficiency. Better and get higher education and social class influence, efficient classroom ought goal is to develop students' lifelong development ability, the paper from the state. The need for efficient design of college English teaching mode and schools are in three areas of social elaborate and high school curriculum continuity. Experience and teaching practice school classroom teaching abroad. Facility security, etc. demonstrate the feasibility of efficient classroom and provide preconditions for exploring efficient classroom teaching.
\end{abstract}

\section{Introduction}

Teaching College English Curriculum target countries are required to develop students' English language proficiency, and enhance their self-learning ability, teaching mode to computer-based English Teaching and classroom, fully reflects the dominant position of leading role of teachers and students, promote development of individualized study methods and the autonomous learning ability, making full use of modern information technology, inherit the traditional teaching model to be reasonable in excellent part, play the advantages of traditional classroom teaching, 2. national education reform and long-term development plan (2010-2020) clearly pointed out the need educating people as a fundamental requirement for education, reform and innovation as a powerful driving force for the development of education, student-centered, teacher-led, give full play to the initiative of students, provide a suitable education for each student, to solve what cultured people. How to cultivate people's major problems for all students? Promote the overall development of students, and strive to improve student services national social responsibility to serve the people. Innovative spirit and practical ability courage to explore the problem solver, 3 for the party's 18 proposed to further education reform full implementation of quality education, deepen comprehensive reform of education, focus on improving the quality of education, cultivating students' innovative spirit,

The current social demand for talent is a practical ability and innovative spirit of compound talents, and the current examination-oriented education stifle students' innovative thinking, if you do not change the current teaching model, still spoon-feeding education, culture will be difficult to 
adapt to social need talent, we need to reform university school teaching high school as a follow-up phase and the person riding in front of social preparation phase, teaching reform is particularly necessary to design and efficiency of classroom directly affects students' mastery of knowledge and ability, is the key teaching reform lies.

\section{Feasibility of Efficient Classroom Teaching Model}

New Curriculum Reform of Primary and Secondary positive surging, which referred to the teaching / teacher-led, student-centered teaching mode reform and complement the reform of primary and secondary schools to further deepen the reform of teaching university foundation,

The theoretical basis of this paper Western constructivist theory, its representatives have Piaget (J.Piaget). Kornberg (O.Kernberg). Sternberg (R.J.Stefnbefg). Katz (D.Katz). Vygotsky (V ah ostgy), its core is student-centered, emphasizing the students' knowledge of active exploration. Active discovery and the knowledge active construction of meaning, and constructivism theory suitable teaching mode: a student-centered, in the whole process of teaching by teachers from the organizers. Director. Helper and the role of facilitator, use context. Learning sessions and other environmental factors, give full play the initiative of students. Enthusiasm and initiative, and ultimately achieving students effectively achieve the significance of the current knowledge of the purpose of the construction, teaching methods Constructivist Teaching Mode main scaffolding instruction. Anchored Instruction. Random into teaching, teaching method includes three independent learning. Collaborative learning and performance evaluation and other sectors, the construction design principles of teaching learning environment is to emphasize student-centered, emphasizing the important role of context for the construction of meaning, emphasizing the key role of collaborative learning on the construction of meaning, emphasizing the ultimate goal is to complete the learning process meaning Construction,

Many Western countries have established teaching this theory, based on the cultivation of students' innovative thinking. Self-learning ability and ability to develop life-long played an active role, such as Chichester University in the UK, is through the teachers guide (Introduetion). Pupils discuss (Diseussion). Display (presentation) and feedback (efedbaek) way of classroom teaching, this teacher-led organization of teaching. Student-centered learning classroom model and evaluation mechanisms to ensure the participation of each student, helps the students to learn the content of the impression, and stimulate their imagination and innovation.

\section{Effective Ways to Build Efficient English Classroom Model}

That the new curriculum, students are learning the subject, all teaching activities should focus on the students to implement and follow up. Independent learning is that students under the effective guidance of teachers were reasonable independent study, students highlight subjectivity participation, students awareness and self-learning ability in independent learning process, students follow culture of learning and ability to lay the foundation for sustainable development. Efficient classroom should enhance consciousness of students and teachers by the dominant enable students to actively participate in teaching practice, independently and develop a variety of learning ability, in order to obtain the necessary knowledge \$ strengthening discipline skills.

Self-centered approach to leading change subjectivity, to guide students at different levels can experience the fun of self-learning and achievement, thereby improving the efficiency of English teaching. In practice, can be summarized as, impression goals, guided self-study, coaching exchange, the use of basic teaching model for the evaluation process. 
Impression goals. As culture shape us of thinking about it, teachers can design the following questions: what is chinatown? Allow students to think for mining and to expand the existing information in the minds of students. This not only makes it natural to introduce students to learn the content of the text, but also can stimulate the curiosity of students, encourage students to take the initiative to the text to find the answers. Guided self-study. Guided self-learning is the key to the teaching process. Practice has proved that: Once the students aware of their exploration and research results achieved recognized, heartfelt joy that shone out of self-confidence, and thus tend to burst out of the intellectual potential is beyond expectation. This will not only experience the joy of success to promote the development capability, more importantly, it is to rely on the ability and confidence to promote the development of further learning, conducive to sustainable development of students.

Coaching exchange. Coaching exchange for self-learning activity was explored still can not solve the problem, teachers inspired \$ explain and highlight the focus of this lesson \$ difficulty in the process, achieve the teaching objectives of this lesson. As Professor passive knowledge through practice, under the premise of the student mastered, teachers can blackboard following sentence we clean the classroom, the classroom is clean by us and guide students to compare, to enable students to understand the two sentences and that the relationship between the main $\$$ difference between the \$ Bin, students will be able to quickly find and summed up: Objects as sentence 1 sentence 2 of the subject, predicate sentence 1 becomes, the past participle of the verb structure, subject sentence 2 . It became, in the form of the object. In this way, the passive voice and difficulty will focus on the easy.

Independent learning is the requirement of quality education, improve their awareness of the need for good soil nurturing environment, to optimize the classroom atmosphere, there really is an important prerequisite for the culture of independent learning. Enhance their independence does not mean a negative carry forward the spirit of equality and mutual assistance between the students, in practice, teachers can form study groups to promote Hubanghuxue between students, teachers praise and criticism can group the overall level of progress or not as the standard, rather than individuals to measure. In addition, when Jacky express their opinions, the same group should listen carefully to other students, and to help proofread, teams are formed opinions, when collective proofreading, training students to do first is certainly the advantage of others, respect for the autonomy of the students, and then express their views . This allows every student feel that they are respected and resulting in a sense of success and pleasure, have a positive attitude to learn. Learning Ways to strengthen and improve the learning ability of students' independent learning advocate, it is not without purpose, sheep. Compared with the traditional teaching methods, to improve the ability of students through independent study, teachers should have more exquisite art of teaching, teachers should strive to, it becomes a one-man, Qunyan Tang, the implementation of quality education to the whole process of classroom teaching. Enable students to understand and master the method of control is more important than specific knowledge, and the master method must be implemented in the main practice. Efficient classroom is specific and concise classroom Objectives Guidance to set specific and refining, imported to be flexible. Teachers should teach science objectives into goals. English teachers should \& English curriculum standards, the contents of the standard refined into each semester \$ each unit and each class learning objectives, learning objectives of each lesson, be specific, Guidance outline designed to refine practical. Import target due to the use of different class and type of flexible and natural way. As the new medium naturally present this lesson in the target after import new lesson. 
Efficient classroom will become the development trend of English teaching is to comply with the State. The only way society and the development of universities, how to draw on the useful experience of domestic and international high class, improving the inadequacies of the current reform of classroom teaching, to explore a college classroom teaching design effective programs to address the circumvention or appear to promote efficient classroom applications problems or barriers to higher education reform is urgently needed to explore the issue.

\section{Conclusion}

Opportunity process of implementing the new curriculum of English, teachers should establish a quality education in line with the spirit of the concept of education, good inspire and guide students to actively participate locomotor activity, according to the textbook and students real life, as much as possible for students to create active learning, active inquiry and conditions help build confidence, so that in the classroom to fully experience the ownership status \$ power and freedom, and thus develop good study habits and the use of effective learning strategies, self-learning ability is formed, for their own lifelong learning and development and lay good foundation.

\section{REFERENCE:}

[1] Harmer. The Practice of English Language Teaching .New Edition [D]. New York: Longman Publishing. 1991.

[2] Lewis, M. How to Study Foreign Languages [D]. New York: Palgrave. 1999.

[3] Brown, H. D. Principles of Language Learning and Teaching [D]. New York: Prentice Hall. 1994.

[4] Brown, H. D. Teaching by Principles, an Interactive Approach to Language Pedagogy [D]. New York: Prentice Hall. 1994. 